Gardner, J. F., James, L. V. \& Rubbo, S. D. (1956). J. gen. Microbiol. 14, 228-237

\title{
Production of Gitric Acid by Mutants of Aspergillus niger
}

\author{
By JOAN F. GARDNER, L. VALERIE JAMES AND S. D. RUBBO \\ School of Bacteriology, University of Melbourne, Australia
}

SUMMARY: Mutants of Aspergillus niger, Wisconsin strain 72-4, were produced by multiple X-ray and ultraviolet irradiation. The mutants differed from the parent strain culturally and in citric acid production. Comparison between the yields of citric acid from the parent strain and mutants showed significant increases with the latter. In crude sugar media, such as ferrocyanide-treated brown sugar, yields of citric acid equivalent to $80 \%$ of the sugar fermented were obtained in aerated culture, whereas only $21 \%$ was obtained with the parent strain.

The factors which govern citric acid production by Aspergillus niger in submerged culture, particularly the influence of the metal constituents of the medium, were investigated in detail by Shu \& Johnson $(1947,1948 a, b)$, and their findings were confirmed and extended by Tomlinson, Campbell \& Trussell $(1950,1951)$. The small amounts of iron, zinc, copper and manganese which are essential for optimal growth (Steinberg, 1935) exceed the concentrations which favour citric acid production. Thus one step towards providing suitable conditions for acid accumulation is to decrease these metal concentrations well below those required for optimal growth. Even so, it is extremely difficult to obtain constantly the highest yields of citric acid, especially from crude cane sugar, by the submerged culture method.

Three approaches to this problem are possible: (1) to strip the medium of its excess metal contaminants by ion-exchange techniques, as described in a patent issued to Miles Laboratories (1952), or by potassium ferrocyanide precipitation (Gerhardt, Dorrell \& Baldwin, 1946; B.I.O.S. Final Report 220, 1946; Clement, $1952) ;(2)$ to add a growth-inhibitory agent such as methanol which was found to increase the metal concentrations permissible (Moyer, 1953); (3) to isolate metal-tolerant mutants.

In regard to this third possibility Perlman (1947), who investigated some seventy-five strains of Aspergillus niger for ability to produce citric acid in submerged culture, found considerable variation among them and reported that some were less affected by metal ions than others. Quilico, Panizzi \& Visconti (1949) obtained mutants by $\mathrm{X}$-ray irradiation which gave increased yields on Currie's defined medium (1917); they did not report on the yields of citric acid obtained from crude sugar substrates. Yuill (1951) commented briefly on citric acid production by mixed cultures of $A$. niger, some of them mutants. He stated that when two unrelated high acid-producing strains were grown together, the yield was lower than that given by either separately, but no such decrease was observed when the strains were related as mutant and parent, or as mutants from the same parent; no information was given about the ability of these mutants to produce acid from crude sugars more efficiently than the parent strain. 
The present work is concerned with the study of citric acid production by mutants of Aspergillus niger in metal-contaminated crude cane sugar by submerged (shaken or aerated and stirred) culture. A method developed for selection of such mutants is described separately (James, Rubbo \& Gardner, 1956).

\section{METHODS}

\section{Organism}

The parent culture was Aspergillus niger Wisconsin strain 72-4 (Perlman, Kita $\&$ Peterson, 1946). For irradiation and fermentation experiments, cultures were grown on the $14 \%$ sucrose agar defined medium described by Shu \& Johnson (1947) and on beer wort agar. On these media sporulation was prolific after 3-5 days of incubation at $28^{\circ}$.

\section{Irradiation techniques}

$X$-ray irradiation. Freshly formed spores were spread aseptically on the surface of a $4 \%$ agar gel and exposed to $X$-rays in doses of 45,000 and 60,000 r. The spores were then washed off the agar with water containing a wetting agent, Soaxit (sodium dioctyl sulphosuccinate, 1/10,000), and the suspension filtered through sterile cotton-wool to remove clumps. The death-rate was estimated by comparison of the viable count (plate method) with a haemocytometer count of the total number of spores, and found to be $99 \%$ with a dose of $45,000 \mathrm{r}$. and $99.9 \%$ with $60,000 \mathrm{r}$. In later experiments $1 \mathrm{ml}$. of an aqueous suspension of spores, previously filtered through cotton-wool and containing $2 \times 10^{6}$ spores, was irradiated in a small Petri dish covered with cellophan.

Ultraviolet irradiation. Filtered suspensions of spores in water, containing $2 \times 10^{6}$ spores $/ \mathrm{ml}$, were irradiated, at room temperature $\left(c .20^{\circ}\right)$ in a clear quartz tube of $2 \mathrm{~cm}$. diameter, by a vertical 15-watt G.E. low-pressure germicidal lamp $(2537 \AA$.). The tube was rotated at 180 r.p.m. with its axis parallel to and $12 \mathrm{~cm}$. from the lamp. The irradiations were performed in a dark room and the irradiated suspensions were shielded from light until plated out in order to minimize any photoreactivation effects. Exposure for $15 \mathrm{~min}$. gave a $99 \cdot 9 \%$ kill.

The plan for preparation of high-yielding mutants was similar to that outlined by Dulaney, Ruger \& Hlavac (1949) for improving streptomycin yields by Streptomyces griseus, in that it involved exposure of the spores of successively induced mutants to mutagenic agents. All strains selected were preserved by lyophilization of spores harvested from beer wort agar.

\section{Fermentation techniques}

Submerged culture methods. Some mutants which showed superior acidproducing ability on cane molasses substrate by surface culture were tested as submerged cultures in flasks on a rotary shaker ( 1 in. throw, 200 r.p.m.) at $\mathbf{2 8}{ }^{\circ}$ and finally in $5 \mathrm{l}$. fermentation flasks equipped for aeration and agitation. 
The shaken flasks, of $\mathbf{5 0 0} \mathrm{ml}$. capacity and loosely plugged with cotton-wool, contained $50 \mathrm{ml}$. of medium. Three preparations containing sucrose were used: white sugar of the ordinary commercial grade; a brown crystalline product ('brown sugar'); cane molasses. Their content of those trace metals important in the fermentation is shown in Table 1.

Table 1. Metal content in different batches of cane sugar

\begin{tabular}{|c|c|c|c|c|}
\hline \multirow{2}{*}{$\begin{array}{c}\text { Type of sucrose } \\
\text { preparation }\end{array}$} & \multicolumn{4}{|c|}{ Metal content (p.p.m.) } \\
\hline & Copper & Iron & Zine & Manganese \\
\hline White sugar & $0 \cdot 06-0 \cdot 20$ & $1 \cdot 42-3 \cdot 00$ & $0 \cdot 24-1 \cdot 00$ & $0 \cdot 45-1 \cdot 40$ \\
\hline Brown sugar & $3 \cdot 3-4 \cdot 7$ & $65-88$ & $1 \cdot 1-5 \cdot 7$ & $1 \cdot 6-7 \cdot 0$ \\
\hline Molasses & $7 \cdot 6-7 \cdot 8$ & $104-360$ & $4 \cdot 4-57$ & $39-49$ \\
\hline
\end{tabular}

All media contained (g./l.): sucrose preparation, $140 ; \mathrm{KH}_{2} \mathrm{PO}_{4}, \mathbf{1} \cdot 0$; $\mathrm{MgSO}_{4} .7 \mathrm{H}_{2} \mathrm{O}, 0 \cdot 25 ; \mathrm{NH}_{4} \mathrm{NO}_{3}, 2.5$. In the case of the white sugar medium, trace metals were added as follows (mg./l.): $\mathrm{CuSO}_{4} .5 \mathrm{H}_{2} \mathrm{O}, 0.2 ; \mathrm{ZnSO}_{4} .7 \mathrm{H}_{2} \mathrm{O}, 1 \cdot 0$; $\mathrm{FeSO}_{4} \cdot 7 \mathrm{H}_{2} \mathrm{O}, 5 \cdot 0$; these being the quantities given by Shu \& Johnson (1947). The $\mathrm{pH}$ value was adjusted to $\mathbf{3 \cdot 0}$ for white sugar, $5 \cdot 6$ for brown and $5 \cdot 0$ for molasses. The flasks were inoculated with a suspension of mycelial fragments prepared in shaken cultures containing plastic beads. Cultures were incubated for 9 days before being analysed for acidity and residual sugar.

For aerated submerged fermentations a battery of four 5 l. round-bottom reaction flasks of Hysil glass mounted in a water-bath at $28^{\circ}$ was used; the equipment was similar to that described by Kelly, Miller \& Hale (1952). Air inlet tubes and baffle plates were glass, stirrers were of glass or stainless steel. The rate of air flow was $4 \mathrm{l} . / \mathrm{min}$. and the speed of the stirrer was 600 r.p.m., both being the maximum obtainable with our equipment.

Fermentations were started by inoculating 11 . of $2 \%$, w/v, sugar medium with $100 \mathrm{ml}$. of a suspension of mycelial fragments. Incubation with aeration for $24 \mathrm{hr}$. produced an actively growing mycelial mass, to which $3 \mathrm{l}$. medium containing high sugar and low ammonium nitrate $(187 \mathrm{~g}$. and $0.83 \mathrm{~g} . / 1$. respectively) were added. The final concentration of sugar in the combined media was $14 \%$.

When potassium ferrocyanide was used in the brown sugar medium it was added to the hot medium after autoclaving, usually $0 \cdot 25-0.50 \mathrm{~g} . /$. for the

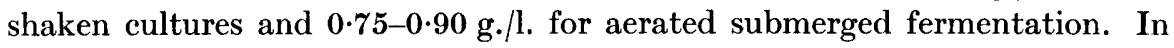
cane molasses a much higher concentration (3.0 g./l.) was required for high yields in shaken cultures.

Acidity was determined by titration with $0.25 \mathrm{~N}-\mathrm{NaOH}$ and residual sugar by Cole's ferricyanide method (1933). At the conclusion of a fermentation the acid products were identified and their proportions estimated by partition chromatography, with butanol + water containing $2 \mathrm{~N}$-formic acid as solvent (Lugg \& Overell, 1948). 


\section{RESULTS}

\section{Origin and description of mutant strains}

The distinguishing cultural characteristics of the strains of Aspergillus niger investigated are shown in Table 2 and Pl. 1. It will be seen that the mutants are easily distinguished by their restricted colony development and delayed sporulation. After 3 days of incubation on Czapek-Dox medium the mutants gave raised non-sporulating compact colonies (popcorn colonies), while the parent strain 72-4 gave a flat spreading colony with spores. When grown on beer wort agar slopes strain 72-4 spored prolifically in 2-3 days whereas, after 7 days, the felt of mutant $X 20$ was unevenly covered with spores. It is interesting to note that mutant $V 7-1$ spored freely only on the upper portion of the slope after 9 days of incubation (Pl. 1), a character shared by all the other mutants except X20.

Table 2. Origin and distinguishing features of Aspergillus niger strains

\begin{tabular}{|c|c|c|c|}
\hline $\begin{array}{c}\text { Aspergillus niger } \\
\text { strain }\end{array}$ & Origin & $\begin{array}{c}\text { Time and degree } \\
\text { of sporulation on } \\
\text { beer wort agar } \\
\text { (days/degree*) }\end{array}$ & $\begin{array}{l}\text { Colony size on } \\
\text { Czapek-Dox agar } \\
\text { after } 8 \text { days } \\
\text { (central point } \\
\text { inoculation) } \\
\text { (diameter, mm.) }\end{array}$ \\
\hline 72-4 (Wild type) & University of Wisconsin & $3 / t+t+$ & 35 \\
\hline X20 (mutant) & X-ray irradiation of $72-4$ & $\boldsymbol{z} /+++$ & 10 \\
\hline V4 (mutant) & UV irradiation of X20 & $9 /++$ & 8 \\
\hline V 4-1 (mutant) & UV irradiation of V 4 & $14 /+$ & 8 \\
\hline V 4-2 (mutant) & UV irradiation of V 4-1 & $14 /+$ & 8 \\
\hline V7 (mutant) & UV irradiation of X20 & $9 /+++$ & 8 \\
\hline V 7-1 (mutant) & UV irradiation of $\mathrm{V} r$ & $9 /++$ & 8 \\
\hline$V 7-2$ (mutant) & UV irradiation of $V 7-1$ & $9 /++$ & 8 \\
\hline
\end{tabular}

When grown on the surface of liquid media the mutants in general developed felts which were lighter and more friable than those of the parent strain 72-4. On cane molasses mutant $V 7-1$ grew as a light, non-sporing felt covering the entire surface of the medium, mutant $\mathrm{X} 20$ grew as an incomplete moderately sporing felt, while the parent strain $72-4$ produced a tough, heavily sporing band of felt restricted to the edge of the medium. Submerged cultures in shaken flasks reflected the restricted mycelial development of the mutants which was seen on solid media. These characteristics, like the fermentative ability, have remained unchanged through many subcultures over the past 2 years.

\section{Fermentative activity in submerged culture}

Fermentations in shaken flask culture with parent strain 72-4 and mutants $\mathrm{X} 20$ and V7-1, using various sugar substrates were studied. The results are summarized in Fig. 1. The average yield from all substrates was higher with the mutants than with the parent culture. With crude sugars the superiority 
of the new strains was most evident. On treated and untreated molasses the yields of acid with mutant V 7-1 were about twice those obtained with mutant $\mathrm{X} 20$, a similar ratio having been obtained in surface fermentation (James et al. 1956).

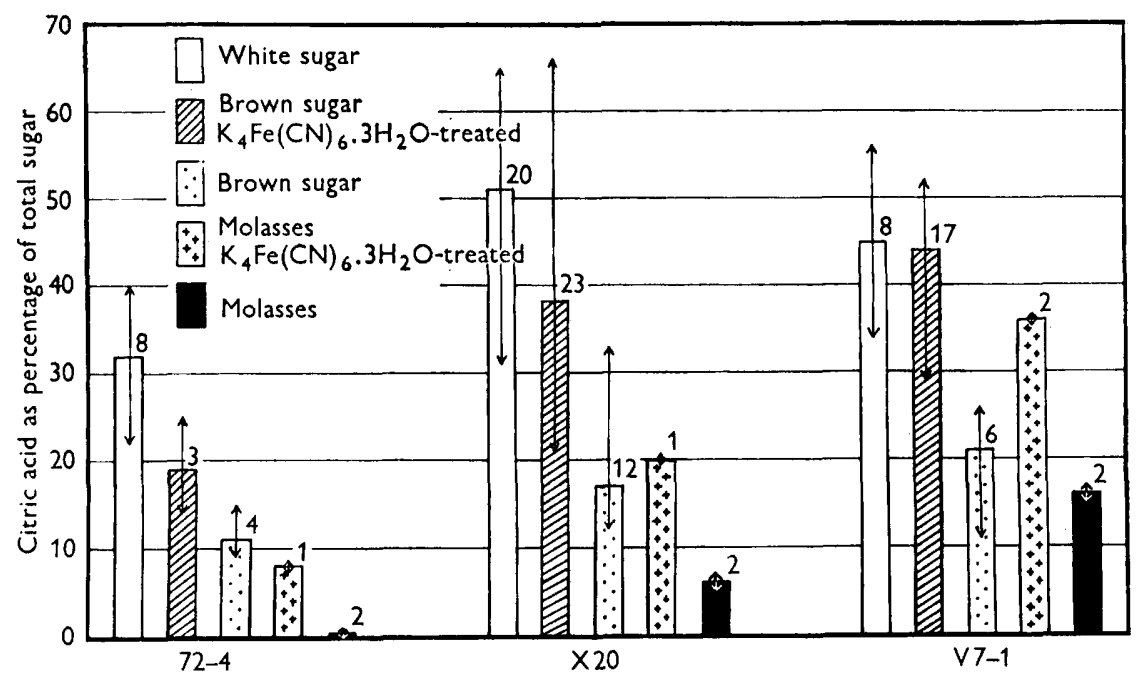

Fig. 1. Average yields of citric acid (columns) and range of variation (arrows with number of fermentations analysed) in 9-day shaken flask cultures at $28^{\circ}$.

The results recorded in Table 3, based on those shown in Fig. 1, indicate that the yields of acid progressively decreased as the metal content of the medium (contributed by the sugar) increased. The loss of efficiency was most pronounced with the parent strain and least with mutant V7-1. However,

Table 3. Influence of substrate on yields of citric acid

Nine-day shaken flask fermentation at $28^{\circ}$.

Yields of citric acid*

\begin{tabular}{|c|c|c|c|c|c|}
\hline Strain & $\begin{array}{c}\text { White } \\
\text { sugar } \\
(\%)\end{array}$ & $\begin{array}{c}\text { Brown sugar } \\
\mathrm{K}_{4} \mathrm{Fe}(\mathrm{CN})_{6} \cdot 3 \mathrm{H}_{2} \mathrm{O}- \\
\text { treated } \\
(\%)\end{array}$ & $\begin{array}{c}\text { Brown sugar } \\
\text { untreated } \\
(\%)\end{array}$ & $\begin{array}{c}\text { Molasses } \\
\mathrm{K}_{4} \mathrm{Fe}(\mathrm{CN})_{6} \cdot 3 \mathrm{H}_{2} \mathrm{O}- \\
\text { treated } \\
(\%)\end{array}$ & $\begin{array}{c}\text { Molasses } \\
\text { untreated } \\
(\%)\end{array}$ \\
\hline $72-4$ & 100 & 61 & 33 & 23 & 0 \\
\hline $\mathbf{X 2 0}$ & 100 & 74 & 32 & 34 & 11 \\
\hline$V 7-1$ & 100 & 98 & 52 & 71 & 32 \\
\hline
\end{tabular}

* For purposes of comparison the yields of citric acid from white sugar are calculated as $100 \%$ and the yields from other sugars adjusted accordingly.

from an industrial point of view, it is apparent that untreated cane molasses is unsuitable as a substrate for citric acid production with the mutants available, although mutant V7-1 gave outstandingly good yields in ferrocyanidetreated sugar or cane molasses. 
In the fermenters, where aeration was combined with mechanical agitation, the results (Fig. 2) generally confirmed the findings with surface and shaken fermentations, mutant $V 7-1$ being superior to mutant $\mathrm{X} 20$ and this in turn superior to parent strain 72-4. It is worth noting that mutant V7-1 in ferrocyanide-treated brown sugar was better in aerated fermenters than in shaken flasks, whereas with mutant $\mathrm{X} 20$ the difference was negligible.

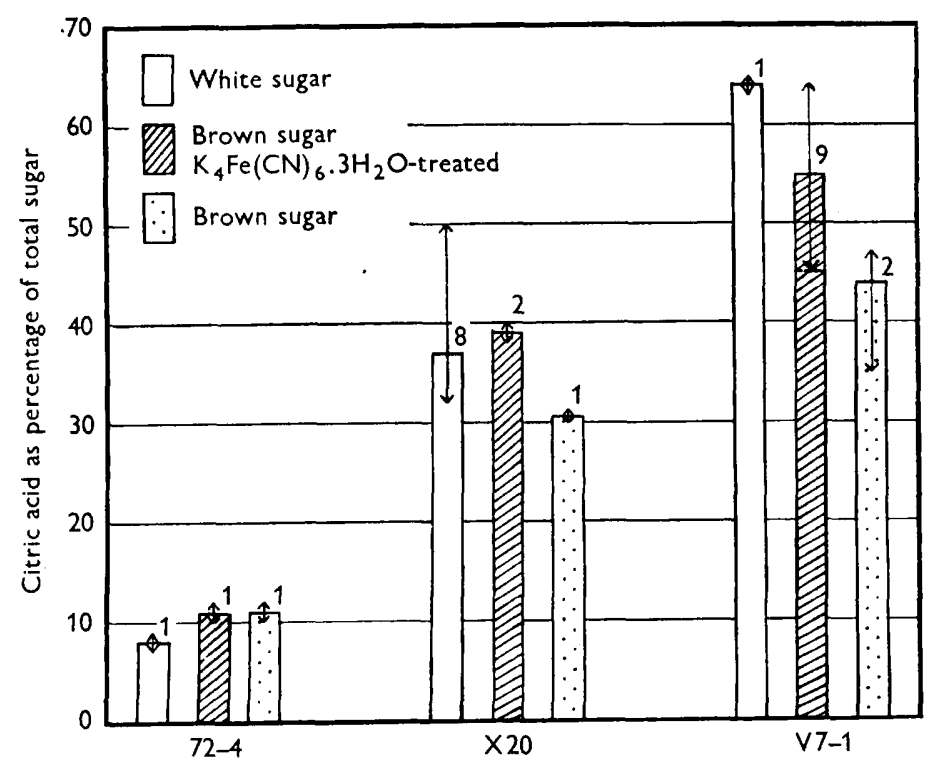

Fig. 2. Average yields of citric acid (columns) and range of variation (arrows with number of fermentations analysed) in 11-day aerated and stirred cultures at $28^{\circ}$.

A closer analysis of the aerated fermentation is given (Fig. 3) for brown sugar media, with and without ferrocyanide treatment. It will be seen that the production of citric acid was most rapid with mutant $V 7-1$, reaching a yield of $64 \%$ in 9-11 days in the ferrocyanide-treated medium. At the conclusion of these fermentations, when the acidity had reached its maximum, the culture fluid usually contained 1-2\% sugar. Therefore, when the results are calculated on sugar consumed the yields are higher than those shown in Figs. 2 and 3, reaching $21 \%$ for the parent strain $72-4,48 \%$ for mutant $X 20$ and $80 \%$ for mutant $V 7-1$ in 9 days in the best runs. Such yields compare favourably with those regarded as satisfactory in an industrial process.

\section{Utilization of citric acid as a substrate}

It was thought that the difference in citric acid production between the parent strain and mutants of Aspergillus niger might be due to differences in their ability to utilize citric acid as a substrate, the parent being more active than the mutants. In order to test this point surface felts and submerged pellets of $A$. niger mycelium were harvested from sucrose medium, washed and 
transferred to a medium containing $6 \%$ citric acid as sole source of carbon. In addition, parallel tests were done in $6 \%$ citric acid medium containing $4 \%$ sucrose. These replacement cultures were incubated at $28^{\circ}$ in static and shaken flasks and the utilization of citric acid determined by titration with $0 \cdot 25 \mathrm{~N}$ $\mathrm{NaOH}$ and also colorimetrically (Saffran \& Denstedt, 1948). The results
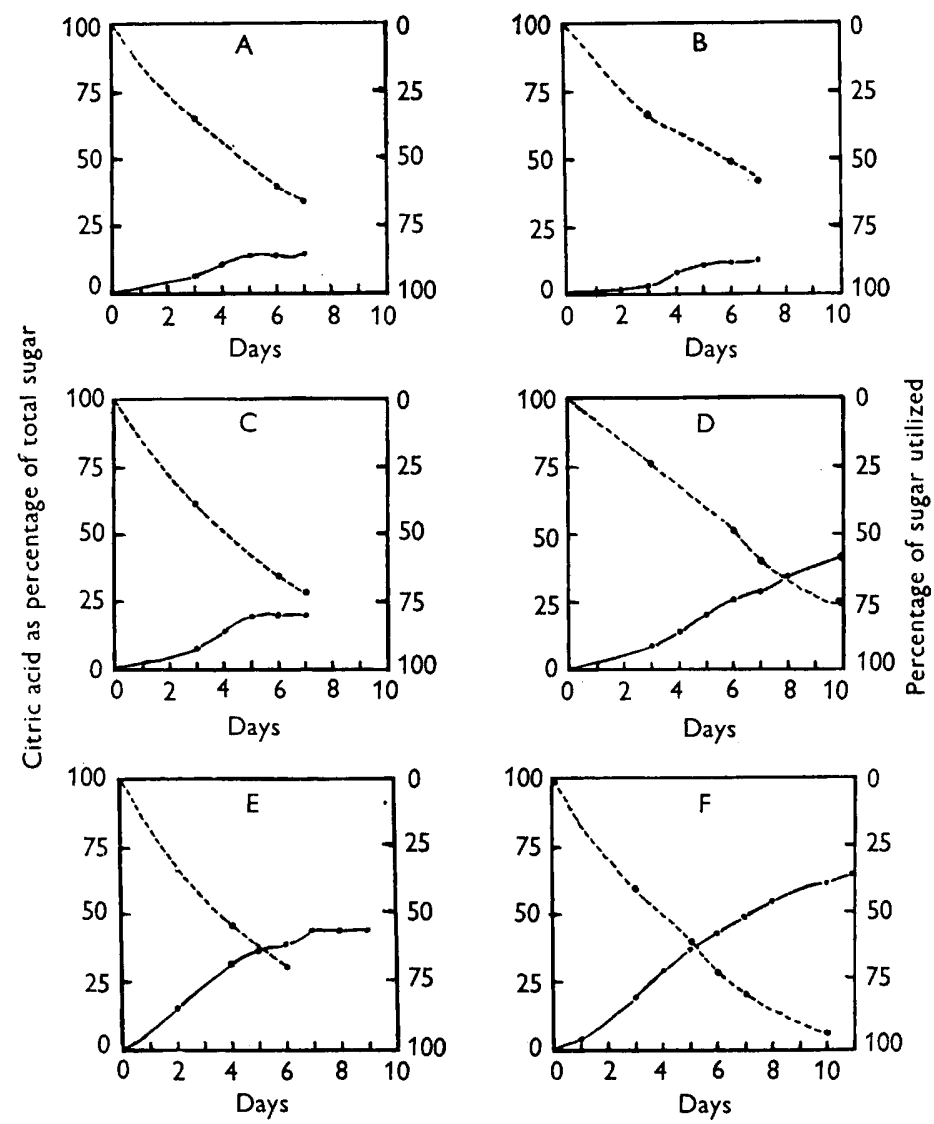

Fig. 3. Rate of citric acid production (-) and sugar utilization (- ---$)$ in aerated and stirred cultures at $28^{\circ}$.

$A, B$, parent strain 72-4 on untreated and on $\mathrm{K}_{4} \mathrm{Fe}(\mathrm{CN})_{6} \cdot 3 \mathrm{H}_{2} \mathrm{O}$-treated brown sugar.

$\mathrm{C}$, D, mutant $\mathrm{X} 20$ on untreated and on $\mathrm{K}_{4} \mathrm{Fe}(\mathrm{CN})_{6} \cdot 3 \mathrm{H}_{2} \mathrm{O}$-treated brown sugar.

$\mathrm{E}, \mathrm{F}$, mutant $\mathrm{V7}-1$ on untreated and on $\mathrm{K}_{4} \mathrm{Fe}(\mathrm{CN})_{6} \cdot 3 \mathrm{H}_{2} \mathrm{O}$-treated brown sugar.

(Table 4) showed that the rate of disappearance of citric acid in both static and shaken cultures was similar for the parent strain and mutants. The discrepancy between the total titratable acid and citric acid estimations, which developed towards the end of the fermentation, indicated that acids other than citric were being produced. When sucrose was present (Fig. 4) there was no apparent utilization of the citric acid by any of the cultures until the sugar concentration had fallen to zero. These findings clearly showed that the high yields of citric acid in the mutant cultures (and their restricted growth rate) 
were not due to their inability to metabolize the citrate formed. In any case it appears unlikely that any of the cultures will attack citrate while sucrose is present in the medium. It is obviously important to take advantage of the citrate-sparing effect of sucrose if highest yields of citric acid are to be obtained commercially.

Table 4. Utilization of citric acid by strains of Aspergillus niger

\begin{tabular}{|c|c|c|c|c|c|c|}
\hline \multirow{4}{*}{ Strain } & \multirow{4}{*}{$\begin{array}{l}\text { Method of } \\
\text { cultivation }\end{array}$} & \multicolumn{5}{|c|}{ Citric acid yield in culture fluid } \\
\hline & & \multicolumn{2}{|c|}{ Initial } & \multirow{2}{*}{$\begin{array}{l}\text { After } \\
\text { 4 days; by } \\
\text { titration }\end{array}$} & \multicolumn{2}{|c|}{ After 7 days } \\
\hline & & \multirow[t]{2}{*}{ Titration } & $\begin{array}{l}\text { Colori- } \\
\text { metric }\end{array}$ & & $\begin{array}{l}\text { By titra- } \\
\text { tion }\end{array}$ & $\begin{array}{l}\text { Colori- } \\
\text { metric- }\end{array}$ \\
\hline & & & \multicolumn{3}{|c|}{ Citric acid (mg./ml.) } & ally \\
\hline \multirow[t]{2}{*}{ Parent 72-4 } & Surface & 59 & 59 & 41 & 13 & 2 \\
\hline & Shaken & 63 & 68 & 12 & 5 & N.D. \\
\hline \multirow[t]{2}{*}{ Mutant X 20} & Surface & 57 & 59 & 26 & 9 & 0 \\
\hline & Shaken & 65 & 70 & $8 \cdot 5$ & $3 \cdot 5$ & N.D. \\
\hline \multirow[t]{2}{*}{ Mutant V7-1 } & Surface & 58 & 59 & 25 & 7 & 0 \\
\hline & Shaken & 66 & N.D. & $13 \cdot 5$ & 2 & N.D. \\
\hline
\end{tabular}

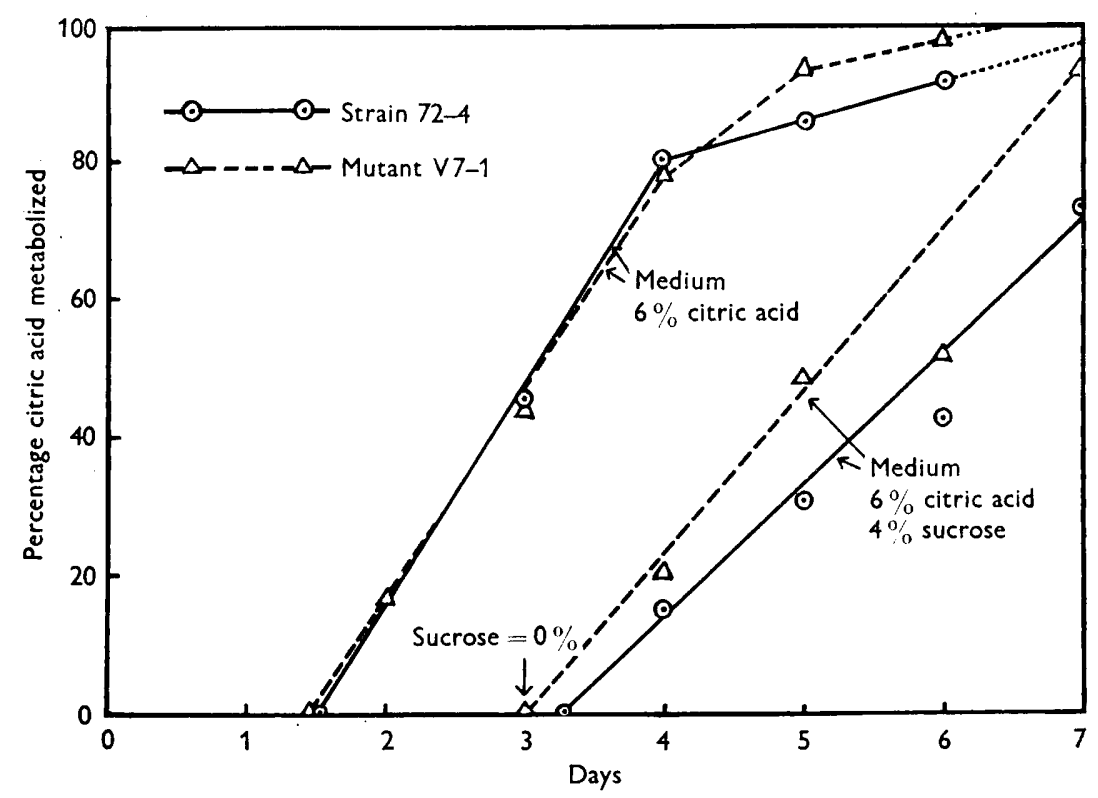

Fig. 4. Utilization of citric acid by strains of Aspergillus niger.

\section{DISCUSSION}

The aim of this investigation was to study the fermentative activity of mutants of Aspergillus niger. These mutants were induced by X-ray and ultraviolet irradiation of spores and selected by paper culture technique 
(James et al. 1956). They were culturally distinct from the parent strain and stable in all characteristics studied.

The results show that all the mutants were markedly more active in producing citric acid than the parent strain under all conditions of fermentation, namely in static, shaken and aerated submerged cultures with commercially pure sucrose or crude sucrose such as cane molasses. In aerated fermentations these differences were most pronounced in that one mutant, $V 7-1$, gave fourfold to sixfold higher yields of citric acid than the parent strain 72-4. Mutant V7-1 appears to be suitable for large-scale production of citric acid since it is capable of giving yields of citric acid equivalent to $80 \%$ of the sugar fermented in ferrocyanide-treated crude brown sugar media. With beet molasses, a substrate similar in metal content to brown cane sugar, comparable results might confidently be expected. Unfortunately, beet molasses was not available to us in the present study.

Several points of interest emerge from this work. In the first place it was apparent that the best strains are multiple-step mutants produced by exposure to mutagenic agents. These differed from the parent strain in requiring up to 9 days for sporulation, in growing as small compact colonies (Table 2 ) and in producing lighter and more friable felts on liquid media as well as smaller amounts of mycelium in submerged culture. The constant correlation between high yields of citric acid and restricted development suggests that the mutants may be deficient in certain metal-dependent enzymes associated with growth, in particular those concerned with the utilization of citrate. Experiments reported here (Table 4, Fig. 4), indicate, however, that the restriction of growth and the enhanced production of citric acid were not concerned with the inability of the mutants to utilize citric acid as a substrate.

The yields quoted for Aspergillus niger 72-4 on white sugar medium are considerably lower than those reported by Shu \& Johnson $(1947,1948 a, b)$; this is probably due to a higher concentration of metals in our media. For example, the concentration of manganese $(60-196 \mu \mathrm{g} . / 1$.$) in the white sugar$ medium was considerably in excess of the optimal level of $1 \mu \mathrm{g} . / 1$. determined by Shu \& Johnson. Little attention was given to the purification of media in this work since our aim was to produce organisms capable of giving high yields of citric acid from impure substrates.

It is with pleasure that the authors thank Kraft Foods Ltd. (Melbourne) for initiating this investigation and providing financial assistance for one of us (J.F.G.). Our thanks are also due to Dr K. T. H. Farrer of the same organization for helpful advice, to Miss A. Macauley for technical assistance and to Prof. W. H. Peterson for supplying the parent culture of Aspergillus niger strain 72-4.

\section{REFERENCES}

B.I.O.S., British Inteiligence Objectives Sub-committee (1946). Final report 220. Production of citric acid at the factory of J. A. Benckiser, Ladenburg, near Heidelberg. 32 Bryanston Square, London, W. 1.

Clement, M. T. (1952). Citric acid fermentation of beet molasses by Aspergillus niger in submerged culture. Canad.J. Tech. 30, 82. 
Journal of General Microbiology, Vol. 14, No. 2

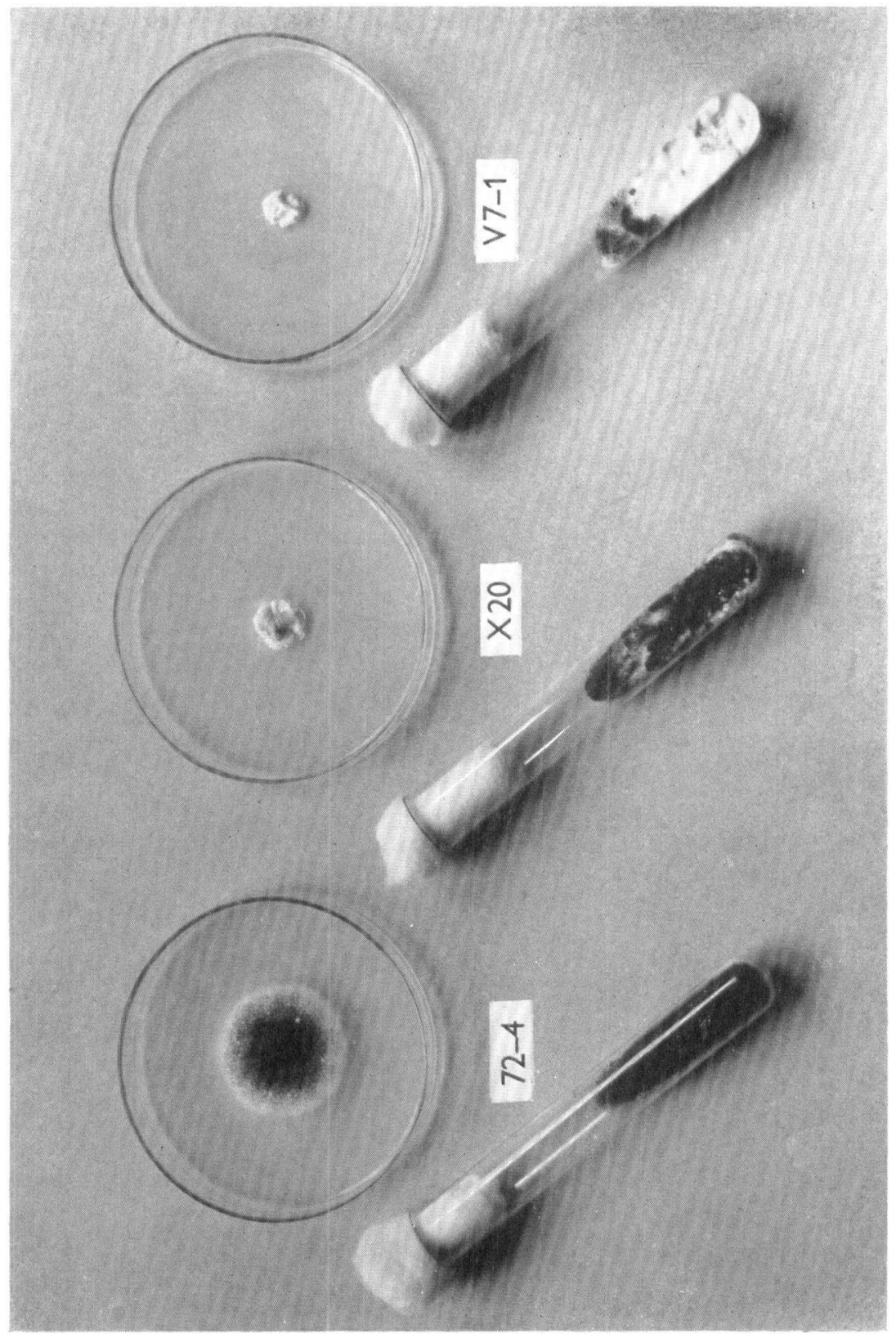

J. F. Gardner, L. V. Jamles \& S. D. Rubbo-Citric acid production By A. niger mutan's. Platel 1

(Facing $p .237$ ) 
Cole, S. W. (1933). Practical Physiological Chemistry, 9th ed. Cambridge: W. Heffer and Sons Ltd.

Currie, J. N. (1917). The citric acid fermentation of Aspergillus niger. J. biol. Chem. $31,15$.

Dulaney, E. L., Ruger, M. \& Hlavac, C. (1949). Observations on Streptomyces griseus. IV. Induced mutation and strain selection. Mycologia, 41, 388.

Gerhardt, P., Dorrell, W. W. \& Baldwin, I. L. (1946). Citric acid fermentation of beet molasses. J. Bact. 52, $\mathbf{5 5 5}$.

James, L. V., Rubbo, S. D. \& Gardner, J. F. (1956). Isolation of high acid-yielding mutants of Aspergillus niger by a paper culture selection technique. J. gen. Microbiol. 14, 223.

Kelly, B. K., Miller, G. A. \& Hale, C. W. (1952). Culture media for large-scale production of micrococin. J. gen. Microbiol. 6, 4.1.

LugG, J. W. H. \& Overell, B. T. (1948). 'One' and 'two-dimensional' partition chromatographic separation of organic acids on an inert sheet support. Aust. J. sci. Res., Series A, 1, 98.

Miles Laboratories (1952). Improvements in the production of citric acid by fermentation of a carbohydrate medium. British Patent No, 669,773. 9 April.

Moyer, A. J. (1953). Effect of alcohols on the mycological production of citric acid in surface and submerged culture. II. Fermentation of crude carbohydrates. Appl. Microbiol. 1, 7.

Perlman, D. (1947). Citric acid production by various strains of Aspergillus niger. Rep. Proc. 4th Congr. int. Microbiol. p. 546.

Perlman, D., Kita, D. A. \& Peterson, W. H. (1946). Production of citric acid from cane molasses. Arch. Biochem. Biophys. 11, 123.

Quilico, A., Panizzi, L. \& Visconti, N. (1949). Richerche sulla fermentazione citrica con mutanti indotti di Aspergillus niger. R.C. Accad. Lincei, 6, 40.

Saffran, M. \& Denstedt, O. F. (1948). A rapid method for the determination of citric acid. J. biol. Chem. 175, 849.

Shu, P. \& Jornson, M. J. (1947). Effect of the composition of the sporulation medium on citric acid production by Aspergillus niger in submerged culture. J. Bact. 54, 161.

Shu, P. \& Johnson, M. J. (1948a). The interdependence of medium constituents in citric acid production by submerged fermentation. J. Bact. 56, 577 .

Shu, P. \& Johnson, M. J. (1948b). Citric acid: production by submerged fermentation with Aspergillus niger. Industr. Engng Chem. 40, 1202.

Steinberg, R. A. (1935). The nutritional requirements of the fungus, Aspergillus niger. Bull. Torrey bot. Cl. 62, 81.

Tomlinson, N., Campreld, J. J. R. \& Trusseld, P. C. (1950). The influence of zine, iron, copper and manganese on the production of citric acid by Aspergillus niger. J. Bact. 59, 217.

Tomlinson, N., Campbelx, J. J. R. \& Trusseld, P. C. (1951). The influence of zinc, iron, copper and manganese on the production of citric acid by Aspergillus niger. II. Evidence for the essential nature of copper and manganese. J. Bact. 61, 17.

Yuill, J. L. (1951). Fermentation with mixed strains of Aspergillus niger. Biochem.J. 49, xix.

\section{EXPLANATION OF PLATE}

Comparison of colonial characteristics ( 6 days, $28^{\circ}$, Czapek-Dox plates) and sporulation (9 days, $28^{\circ}$, on beer wort agar slopes) of the parent strain 72-4 and mutants X 20 and V7-1. 